\title{
Sensory Hearing Loss
}

National Cancer Institute

\section{Source}

National Cancer Institute. Sensory Hearing LosS. NCI Thesaurus. Code C26973.

Hearing loss caused by damage to the cochlea in the inner ear. 